\title{
AMIZADE, PRAZER E FELICIDADE: RELAÇÕES ENTRE ATRIBUTOS E VALORES NA ÓTICA DE CONSUMIDORES DE COMIDA JAPONESA
}

\section{RESUMO}

\author{
Joiza Angélica do Carmo \\ Mestre em Administração pela UFC \\ joiza@ufpi.edu.br
}

Recebido em 26/setembro/2011

Aprovado em 19/agosto/2012

Este trabalho tem como objetivo analisar a relação entre atributos e valores percebida por consumidores de comida japonesa de Fortaleza. A pesquisa sustenta-se teoricamente em abordagens sobre o comportamento do consumidor e em valores, e na Teoria da Cadeia de Meios e Fins (Means End Chain - MEC). Foram realizadas trinta entrevistas em profundidade com consumidores de comida japonesa da cidade de Fortaleza entre os meses de novembro de 2008 e abril de 2009. A técnica aplicada é a laddering, alicerçada nas implicações vislumbradas na Teoria MEC, com o conceito central de "escada de mão", explorando os três níveis: atributos, consequências e valores. Essa técnica proporcionou a construção de uma matriz de implicação e de um mapa hierárquico de valor, que permitiram confirmar os elementos, os atributos, os valores e as consequências que caracterizam o comportamento do consumidor orientado para o prazer e para a satisfação pessoal. O resultado da pesquisa evidenciou, entre os consumidores, valores individualistas como: abertura, vida excitante, satisfação, prazer, felicidade, autoestima e relação afetiva, amizade. Esses valores reafirmam a busca por atingir a meta pessoal. Pela análise do mapa hierárquico de valores, pode-se concluir que esses valores estão relacionados com atributos percebidos pelo consumidor, tais como: ambiente do restaurante; qualidade; comida crua e exótica; cheiro, cor e sabor típicos.

Palavras-chave: Comportamento do consumidor. Comida japonesa. Valores. Cadeia de meios e fins. Laddering..

\section{ABSTRACT}

This paper aims to analyze the relation between attributes and values perceived among the consumers of Japanese food in Fortaleza, Brazil. The research is theoretically based upon in consumer behavior approaches, values and Means End Chain Theory (MEC). There were made thirty in depth interviews with Japanese food consumers in Fortaleza city, between November 2008 and April 2009. The applied technique was laddering, that is based in the viewed implications in MEC Theory, with the central concept of 'hand ladder', exploring three levels: attributes, consequences and values. This technique allowed building an implication matrix and a hierarchical value map, which confirmed elements, attributes, consequences and values that characterize the behavior of the consumer-oriented pleasure and personal satisfaction. The results evidence, among the consumers, individualistic values as: openness, exiting life, satisfaction, pleasure, happiness, self-esteem and affective relationship, friendship. These values confirm their look for achieving personal goal. Through the analysis of the hierarchical value map, it may be concluded that these values are related with attributes perceived by the consumer, such as: restaurant's environment, quality, raw and exotic food, typical smell, color and flavor.

Key words: Consumer behavior. Japanese food. Values. Means End Chain. Laddering. 


\section{INTRODUÇão}

A integração dos mercados, em particular o mercado de alimentos, democratiza os sabores de várias culturas, permitindo ao consumidor fazer escolhas e ter a curiosidade estimulada para conhecer outro paladar. As múltiplas ofertas de produtos e serviços tornam o processo de compra mais complexo. Em decorrência desses fatores, o setor alimentício tem procurado se adaptar às novas demandas, ampliando as opções de escolha para os consumidores. Implica dizer que o setor de alimentos não assume o restrito papel de oferecer comida, mas também a responsabilidade de ofertar um conjunto, em que produto e serviço visam responder de maneira satisfatória às novas exigências do mercado consumidor.

A busca pela satisfação, pelos estados de realização, pelos sentimentos de poder e pelo reconhecimento social são alguns valores conferidos em pesquisas realizadas em diversas sociedades (ROKEACH, 1968; SCHWARTZ, 1992; TAMAYO; SCHWARTZ, 1993; SCHWARTZ; SAGIE, 2000). O ato de alimentar-se, além do simples atendimento fisiológico, é também uma representação social e um meio de integração. Verifica-se que consumidores adotam estilos de vida que influenciam o que consomem. Com base na imagem que possuem de si mesmos e na imagem que gostariam de ter, passam a expressar ideias e ações em seu cotidiano por meio de seu consumo, em forma de rotinas e hábitos (SALVI, 2008).

Diante desses esclarecimentos, este artigo propõe a compreensão de elementos concernentes ao comportamento do consumidor de comida japonesa de Fortaleza, Ceará, evidenciando significados das representações dos atributos, das consequências e dos valores percebidos pelos consumidores. Os atributos percebidos nos alimentos são conectados às consequências de consumo e aos valores pessoais dos consumidores por meio de um mapa hierárquico de valores, que permite identificar os domínios motivacionais que conduzem ao consumo desse tipo de alimento.

O artigo segue com um breve referencial sobre comportamento do consumidor e sobre valores pessoais no consumo. Na sequência, o método de pesquisa expõe informações relacionadas ao objeto de análise e à técnica laddering (REYNOLDS; GUTMAN, 1988), utilizada para a coleta, a análise e a interpretação dos dados. Na seção de resultados, são apresentados o mapa hierárquico de valores e a matriz de implicação, que evidenciam características comportamentais de compra. O último tópico é dedicado às conclusões do estudo de campo e às articulações com o conteúdo teórico relacionado.

\section{Comportamento Do Consumidor}

O estudo do comportamento do consumidor caracterizase pela interdisciplinaridade, buscando em ciências como a antropologia, a sociologia e a psicologia subsídios para melhor compreensão da natureza do homem como indivíduo e consumidor na sociedade.

Estudar o comportamento do consumidor, segundo Vilas Boas (2005, p. 19), consiste em "entender as razões que motivam um indivíduo ou grupo de pessoas a adquirir determinado produto", constituindo-se num dos maiores desafios empreendidos pelos estudiosos da teoria de marketing. Assim, a construção de modelos aplicáveis com capacidade de auxiliar a identificação de fatores que estimulam a motivação do consumo tem se assinalado como uma das linhas de pesquisa de ampla representatividade ligada ao estudo do comportamento do consumidor. Solomon (2002, p. 24) expõe que "o comportamento do consumidor inclui estudar os processos envolvendo indivíduos ou grupos que selecionam, compram, usam ou dispõem de produtos, serviços, ideias ou experiências para satisfazer suas necessidades e desejos”. Em concordância, Engel, Blackwell e Miniard (2000, p. 4) definem comportamento do consumidor como "as atividades diretamente envolvidas em obter, consumir e dispor de produtos e serviços, incluindo os processos decisórios que antecedem e sucedem estas ações”.

Sob a perspectiva da influência de valores pessoais no consumo, Solomon (2002) ressalta que valores latentes acionam as motivações do consumidor, provocando significado instrumental do produto ao permitir o alcance de metas atreladas a um valor. Portanto, conhecer o comportamento do consumidor repousa, basicamente, em entender as razões que o levam a preferir determinados produtos/marcas, na crença de 
que eles poderão lhe oferecer benefícios esperados. Entre as abordagens para a compreensão desse fenômeno, a abordagem de valores pessoais como determinante de compra tem sido utilizada por diversos autores nesse âmbito, tais como: Reynolds e Gutman (1988); Gutman (1991); Reynolds, Gengler e Howard (1995); Leão e Mello (2001); Veludo de Oliveira e Ikeda (2004); Padel e Foster (2005); Vilas Boas (2005); Pimenta et al. (2007); Krystallis, Maglaras e Mamalis (2008); Pimenta et al. (2009). A seguir, são apresentadas considerações teóricas a respeito dessa abordagem.

\subsection{Valores e Comportamento do Consumidor}

Os valores, ao longo dos tempos, têm auxiliado na explicação das mudanças da sociedade, incluindo o comportamento das pessoas e o julgamento das ações, além de terem diferenciado nações e grupos (PORTO; TAMAYO, 2003). Para Schwartz e Bilsky (1987), os valores são representações cognitivas de exigências humanas universais: necessidades biológicas, exigências de interações sociais e demandas institucionais sociais do indivíduo. Um valor para Rokeach (1973, p. 5) é "uma convicção duradoura que um modo específico de conduta ou fimestado de existência é pessoalmente ou socialmente preferível a um oposto modo de conduta ou fim-estado de existência”. Na concepção de Kamakura e Novak (1992, p. 119), os “valores são mais estáveis e ocupam uma posição mais central que atitudes, dentro do sistema cognitivo de uma pessoa”. Contribuindo com essa percepção,
Tamayo e Schwartz (1993, p. 3) entendem e expressam que "a psicologia considera os valores como um dos motores que iniciam, orientam e controlam o comportamento humano. Eles constituem um projeto de vida e um esforço para atingir metas de tipo individual ou coletivo”.

Segundo Rokeach (1968, p. 551), pode ser dito que "todos os seres humanos têm dois tipos de sistemas de valores - um sistema de valor instrumental e um sistema de valor terminal”. Esse autor reduziu, por meio de entrevistas, um vasto número de valores mencionados na literatura. Baseando-se nas análises empíricas de sua pesquisa, concluiu que “é improvável que 36 valores possam ser efetivamente reduzidos para um número menor de fatores” (ROKEACH, 1973, p. 44). Então, desenvolveu o RVS (Rokeach Value Survey) com o objetivo de identificar a prioridade de cada valor na vida da pessoa. Criou uma lista com valores terminais (representando metas de vida desejadas/estados finais desejáveis) e valores instrumentais (representando modos de viver desejados/modos de condutas), os quais foram colocados pelos entrevistados na ordem de importância pessoal. A lista é descrita no Quadro 1.

\begin{tabular}{|c|c|}
\hline $\begin{array}{c}\text { Valores terminais de Rokeach } \\
\text { (objetivos/metas finais de existência) }\end{array}$ & $\begin{array}{c}\text { Valores instrumentais de Rokeach } \\
\text { (meios comportamentais para alcançar as metas } \\
\text { finais) }\end{array}$ \\
\hline 1. Uma vida com conforto (uma vida próspera). & $\begin{array}{l}\text { 1. Ambicioso (trabalhador aplicado, com aspirações } \\
\text { por sucesso). }\end{array}$ \\
\hline 2. $\quad$ Uma vida excitante (uma vida estimulante e ativa). & 2. $\quad$ Liberal (mente aberta). \\
\hline 3. Uma sensação de realização (contribuição duradoura). & 3. $\quad$ Capaz (competente, efetivo). \\
\hline 4. $\quad$ Um mundo em paz (livre de guerra e conflitos). & 4. $\quad$ Alegre (despreocupado, divertido). \\
\hline 5. Um mundo de beleza (beleza da natureza e da arte). & 5. $\quad$ Limpo (organizado, arrumado). \\
\hline $\begin{array}{ll}\text { 6. Igualdade (irmandade, oportunidades iguais para } \\
\text { todos). }\end{array}$ & 6. Corajoso (defende suas opiniões). \\
\hline 7. $\quad$ Segurança familiar (cuidando das pessoas que ama). & $\begin{array}{l}\text { 7. Que perdoa/Magnânimo (disposto a perdoar os } \\
\text { outros). }\end{array}$ \\
\hline 8. $\quad$ Liberdade (independência, livre escolha). & $\begin{array}{ll}\text { 8. Prestativo (trabalhando para o bem-estar dos } \\
\text { outros). }\end{array}$ \\
\hline 9. $\quad$ Felicidade (satisfação). & 9. $\quad$ Honesto (sincero, verdadeiro). \\
\hline 10. Harmonia interior (livre de conflitos internos). & 10. Imaginativo (audacioso, criativo). \\
\hline 11. Amor maduro (intimidade sexual e espiritual). & 11. Independente (autoconfiante). \\
\hline 12. Segurança nacional (proteção contra ataques). & 12. Intelectual (inteligente, reflexivo). \\
\hline 13. $\quad$ Prazer (uma vida agradável, calma). & 13. Lógico (consistente, racional). \\
\hline 14. Salvação (salvo, vida eterna). & 14. Amoroso (afetuoso, carinhoso). \\
\hline 15. Autorrespeito (autoestima). & 15. Obediente (age como o esperado, respeitoso). \\
\hline 16. Reconhecimento social (respeito, admiração). & 16. Educado (cortês, com boas maneiras). \\
\hline $\begin{array}{l}\text { 17. Verdadeiras amizades (companheirismo dos amigos } \\
\text { íntimos). }\end{array}$ & 17. Responsável (seguro, confiável). \\
\hline 18. Sabedoria (entendimento maduro sobre a vida). & $\begin{array}{l}\text { 18. Autocontrolado/que tem autocontrole (moderado, } \\
\text { autodisciplinado). }\end{array}$ \\
\hline
\end{tabular}

Fonte: Adaptado de Rokeach (1973, p. 359 e 361). 
Em complemento a essa abordagem, Schwartz (1994), baseando-se nos 36 valores propostos por Rokeach (1973) e procurando resolver a questão de classificá-los, mostrou que valores podem ser categorizados dentro de dez domínios, simplificados em quatro domínios maiores, conforme mostra o Quadro 2 a seguir.

Quadro 2 - Modelo de Schwartz para a classificação de valores

\begin{tabular}{|c|c|}
\hline Dimensão de valor & Tipo de Valor \\
\hline \multirow[t]{2}{*}{ Autoaprimoramento } & Poder: poder social, autoridade, riqueza, \\
\hline & Realização: sucesso, capacidade, ambição, prazer, diversão. \\
\hline \multirow[t]{3}{*}{ Abertura à mudança } & Hedonismo: prazer, diversão, valores individuais e momentâneos. \\
\hline & Estimulação: vida sem rotina, excitante e desafiante. \\
\hline & Autodirecionamento: criatividade, curiosidade, liberdade. \\
\hline \multirow[t]{2}{*}{ Autotranscendência } & Universalismo: cabeça aberta, justiça social, igualdade, proteção para o ambiente. \\
\hline & $\begin{array}{l}\text { Benevolência: capacidade de visar o bem-estar das pessoas, solicitude, honestidade, } \\
\text { clemência. }\end{array}$ \\
\hline \multirow[t]{3}{*}{ Conservadorismo } & $\begin{array}{l}\text { Tradição: compromisso e aceitação de questões culturais do ambiente onde se está } \\
\text { inserido, humildade, devoção, gratidão. }\end{array}$ \\
\hline & $\begin{array}{l}\text { Conformidade: cortesia, obediência, honradez. Moderação de ações que possam } \\
\text { prejudicar terceiros. }\end{array}$ \\
\hline & Segurança: ordem social, limpeza, cuidado, harmonia social e individual. \\
\hline
\end{tabular}

Fonte: Adaptado de Schwartz (1992).

Como se observa no Quadro 2, Schwartz expõe o conceito de valor como uma crença do indivíduo numa meta terminal ou instrumental, que transcende situações e expressa interesses em alguma de suas dimensões individualistas, coletivistas ou mistas, correspondentes a um domínio motivacional relacionado ao hedonismo, ao poder, à tradição, ao universalismo, sendo avaliada em uma escala de importância (nada importante, muito importante) como um princípio que guia a sua vida (SCHWARTZ; BILSKY, 1987). O modelo teórico de Schwartz, segundo Gouveia et al. (2001, p. 134), é nitidamente uma expansão da estrutura de valores instrumentais e terminais sugerida por Rokeach (1968), apresentando três diferenças fundamentais: a) a proposta de uma medida que combina intervalos com dois valores: um valor considerado de máxima importância e outro identificado como contrário aos demais valores do respondente; b) a ênfase na base motivacional como explicação para a estrutura dos valores; c) a alusão à universalidade da estrutura e do conteúdo dos tipos motivacionais de valores.

Os valores aqui discorridos estão relacionados a motivações que vão desde a dimensão individualista à social. As características e finalidades de consumo podem determinar por qual tipo de valor o consumidor em foco é orientado, ou seja, é possível identificar a predominância de uma dimensão motivacional relacionada a esse comportamento. O consumo hedônico, por apresentar relação estreita com anseios pessoais e emocionais do consumidor, marca o processo de compra ou consumo como um momento lúdico.

Diante das teorias aqui expostas, sugere-se a influência de valores como guia do comportamento nas preferências e escolhas de consumo.Dessa forma, tais conceitos oferecemsustentação para o estudo em sua fase empírica, permitindo a análise dos resultados com melhor compreensão e interpretação dos caminhos percorridos pelos respondentes desta pesquisa.

\section{Metodologia}

Quanto à abordagem do problema, a pesquisa é do tipo qualitativa, que tem, portanto, o interesse de proporcionar melhor visão e compreensão do contexto da questão, que gira em torno do comportamento do consumidor de comida japonesa de Fortaleza e a relação entre atributos do produto e valores desses consumidores. Por se tratar de um tema até o momento não contemplado em outros estudos sob o enfoque da Teoria da cadeia de meios e fins e com uso da técnica laddering, adotou-se processo flexível e não estruturado (MALHOTRA, 2001), 
para melhor atender às particularidades e às demandas do modelo utilizado na investigação, conforme orientação da literatura acerca da citada técnica.

Adotou-se a abordagem direta com os seus potenciais respondentes sobre os objetivos do estudo, bem como o esclarecimento sobre a estrutura da entrevista, no intuito de facilitar o processo de coleta de dados. Os instrumentos utilizados para a coleta foram questionário sociodemográfico e entrevista em profundidade. O objeto de estudo da pesquisa se constitui de consumidores residentes na cidade de Fortaleza, escolhidos sob o critério de ser consumidor de comida japonesa há pelo menos um ano e de consumi-la com a frequência mínima de uma vez ao mês, pois se acredita que esse consumidor terá condições de identificar os atributos do produto, bem como revelar suas percepções acerca de consequências ou benefícios decorrentes do consumo.

Para orientar a coleta, foram seguidos os pressupostos da técnica qualitativa laddering na análise e na interpretação dos dados de campo. A laddering se refere a uma detalhada técnica de entrevista individual, usada para desenvolver uma compreensão de como consumidores traduzem os atributos de produtos e estabelecem associações significantes com respeito ao ego, seguindo a Teoria da Cadeia de Meios-Fins (GUTMAN, 1982; REYNOLDS; GUTMAN, 1988). Na etapa da entrevista em profundidade, foi aplicada a técnica de progressão, cuja "linha de questionamento deriva das características do produto para as características do usuário, permitindo ao pesquisador identificar os diferentes significados atribuídos a um objeto ou problema” (MALHOTRA, 2001, p. 164).

De modo a prover uma abordagem capaz de conectar os valores do consumidor com seu comportamento de compra, Gutman (1982) sugere um modelo com base na Teoria da Cadeia de Meios e Fins (Means End Chain Theory - MEC). No âmbito do marketing, a MEC Theory pode contribuir na identificação tanto dos valores de consumidores bem como do potencial que determinados produtos (meios) têm de atender a tais valores (fins) por meio de seus atributos percebidos. "A cadeia de meios e fins busca explicar como a seleção de um produto ou um serviço facilita a realização dos estados fins desejados” (GUTMAN, 1982 p. 60). A principal ideia da cadeia de meios e fins consiste em que todo produto tem atributos que conduzem a benefícios e valores. Essa sequência de atributos, de consequências e de valores é o foco do modelo. Envolve uma entrevista direta, usando questões que expressam uma meta de determinado jogo de ligações entre os elementos perceptivos chave, ligando os atributos (A), as consequências (C) e os valores (V). Essas redes de associações ou “escada de mão”, referidas para as orientações perceptuais, representam combinações de elementos que servem de base para distinção entre produtos numa determinada classe (GUTMAN, 1982; REYNOLDS; GUTMAN, 1988).

Foram entrevistados 30 consumidores de comida japonesa no período de novembro de 2008 a janeiro de 2009, que atenderam ao critério adotado pelo pesquisador, conforme citado anteriormente - ser consumidor da comida japonesa há pelo menos um ano e consumir o produto com a frequência mínima de uma vez ao mês.

O procedimento para a captação de respondentes inicialmente se constituiu de uma abordagem ao potencial respondente, baseada nos seguintes questionamentos: "Você consome comida japonesa? Há quanto tempo? Qual a frequência de consumo?” Esse foi, portanto, o conjunto de perguntas-chave para compor o perfil do respondente da pesquisa, que era, então, convidado a participar do presente estudo. Após a concordância do entrevistado em participar, ainda nessa etapa, realizavam-se o seu cadastro e o agendamento de sua entrevista. Vale ressaltar que previamente foi feito o devido esclarecimento dos objetivos da referida pesquisa. As entrevistas foram realizadas nos locais e horários indicados pelos respondentes, com o intuito de deixá-los mais seguros e confortáveis, e assim oferecer um ambiente favorável à realização da entrevista.

Tendo em vista a profundidade no processo de entrevista, a técnica laddering aponta algumas diretrizes para a coleta de dados primários (REYNOLDS; GUTMAN, 1988):

a) Em entrevistas em profundidade, gravadas em áudio, são feitas questões do tipo: "Por que isto é importante para você?”, de forma repetitiva, a fim de que sejam revelados os atributos percebidos, por exemplo, "Por que é importante comer comida japonesa para 
você?”.

b) Num segundo momento, é feita a transcrição do texto, a análise de conteúdo e a codificação dos termos identificados, bem como o desenvolvimento da relação de códigos sumários que reflitam o que foi mencionado pelo entrevistado. Primeiro são classificadas todas as respostas nos três níveis: atributos, consequências obtidas pelo consumo desses atributos e valores pessoais, convertendo-os em códigos-resumo individuais.

c) Definidos os códigos-resumo, são atribuídos números a cada um, o que é seguido da construção da matriz de implicação, que contabiliza a quantidade de ligações entre cada código-resumo identificado.

d) Estabelecida a quantidade de ligações dos códigos, passa-se à construção do mapa hierárquico de valores, um tipo de mapa cognitivo que se distingue das análises tradicionais de fator ou dos métodos de escala multidimensional, representativo das associações naturais dos níveis de abstração percebidos pelo consumidor.

Essa técnica tem sido bastante utilizada em pesquisa na área de marketing e, sobretudo, em estudos desenvolvidos sobre o comportamento do consumidor de alimentos (REYNOLDS; GUTMAN, 1988; GUTMAN, 1991; REYNOLDS; GENGLER; HOWARD, 1995; FERRAN; GRUNERT, 2007; PADEL; FOSTER, 2005; VILAS BOAS, 2005; VELUDO DE OLIVEIRA; IKEDA; CAMPOMAR, 2006; KOLAR, 2007; PIMENTA et al., 2007; KRYSTALLIS; MAGLARAS; MAMALIS, 2008; PIMENTA, 2008; PIMENTA et al., 2008; VILAS BOAS, 2008; SAMPAIO, 2009).

Reconhecendo a dificuldade, em algumas circunstâncias, de perceber melhor a opinião do respondente e o seu comportamento diante do produto ou serviço, são apresentadas algumas estratégias de identificação dos atributos do produto para assim ser possível compreender a relação que o consumidor estabelece com o produto/serviço.

Desse modo, o esboço geral da entrevista inclui diferentes métodos para fazer distinção dos elementoschaves, conforme Reynolds e Gutman (1988): 1) Triadic Sorting (escolha de tríade). Proporciona ao respondente jogos de três produtos como procedimento para extrair respostas de um respondente; 2) diferença de preferênciaconsumo, método que também pode ser um dispositivo proveitoso para extrair distinções. Os respondentes, depois de proverem uma ordem de preferência, podem ser instados a citar marcas ou produtos e a contar por que preferem este ou aquele produto ou simplesmente a dizer o motivo da preferência de um produto; 3) diferença por ocasião. Na maioria dos casos, é desejável apresentar ao respondente um contexto pessoalmente significante. Segundo Veludo-de-Oliveira e Ikeda (2004, p. 202), “o cliente é inserido em um contexto de consumo, em que descreve as características relativas a esse consumo”.

Nesta pesquisa, na fase inicial da entrevista, optou-se pela utilização dos métodos triadic sorting e "preferências de consumo", valendo frisar que, em menor frequência, também foi aplicado o método "diferenças por ocasião", este último recomendado em casos específicos, para facilitar a coleta de dados em que o entrevistado não consegue evoluir dos níveis inferiores (atributos) pesquisados.

Admitindo-se as limitações da técnica laddering no que tange ao processo de coleta de dados, podem ocorrer ocasiões em que o respondente de fato não consiga responder ao ser questionado quanto às motivações de sua preferência por determinado atributo e, por conseguinte, não alcance um nível de abstração elevado (REYNOLDS; GUTMAN, 1988). Diante dessas possíveis situações ou problemas, os autores referidos apontam o uso de técnicas para uma melhor obtenção das informações almejadas: 1) evocação de uma situação contexto; 2) simulação da ausência de um objeto ou estado desejado; 3) Negative Laddering: muito pode ser apreendido pela investigação das razões por que os respondentes não fazem certas coisas; 4) contraste pela regressão no tempo: em caso de frases como "não sei responder", pode-se perguntar ao entrevistado por que, agora, ele consome o produto; 5) sondagem na terceira pessoa: "você acha que seus amigos pensam da mesma forma?”; 6) redirecionamento: pode ser usado o silêncio por parte do entrevistador para fazer o respondente continuar tentando encontrar uma resposta mais apropriada. Reynolds e Gutman (1988, p. 12) afirmam que, na técnica laddering, esses elementos foram sequencialmente elucidados para causar no respondente um pensamento crítico das conexões entre os atributos 
dos produtos e, nesse caso, com as suas motivações pessoais.

No processo de coleta de dados desta pesquisa, foi bastante aplicado o subsídio "evocação de uma situação contexto”, condição que permite a inserção do respondente e constitui uma forma de ajudá-lo a formular respostas que evidenciem o seu comportamento, a sua forma de traduzir seu pensamento, seus sentimentos e anseios. Outro mecanismo utilizado com alguns respondentes foi a técnica de redirecionamento, deixando que o entrevistado, por certo tempo, buscasse em sua lembrança a melhor resposta, mesmo que implicasse redundância em seu discurso.

\subsection{Construção da Matriz de Implicação E do Mapa Hierárquico de Valores}

A matriz de implicação assume a estrutura de uma matriz quadrada ao representar todas as relações alcançadas por meio das entrevistas, refletindo o número de elementos os quais se quer mapear, ou seja, o número total de representações de atributos, consequências e valores (VILAS BOAS, 2005). Segundo Gengler (1995), a matriz de implicação serve como um método de atravessar a abertura entre os aspectos qualitativos de laddering para a análise quantitativa das relações entre conceitos. Essas relações, segundo Reynolds e Gutman (1988), são definidas na matriz mediante a representação numérica delas, ou seja, pelo estabelecimento de quais elementos de uma linha precedem outros elementos em uma mesma linha e quantas vezes a relação ocorre. Essas relações são classificadas como diretas (quando nenhum elemento atributo, consequência ou valor intermediário ocorre entre os elementos analisados) e indiretas (quando há a existência de elementos intermediários entre os analisados) e são representadas de forma quantitativa na matriz. O número de relações existentes entre os elementos é apresentado na matriz sob a forma de fração, em que as relações diretas aparecem à esquerda do ponto final, e as indiretas, à direita (VELUDO DE OLIVEIRA; IKEDA, 2004).

Referente ao tratamento de dados obtidos por meio da laddering, verifica-se a possibilidade de utilização de softwares que oferecem subsídios no processo de construção da matriz de implicação e mapa hierárquico de valores (MHV). Atualmente existem softwares como o Laddermap, desenvolvido por Gengler (1995), e o Mecanalyst, desenvolvido e utilizado por Naspeti e Zanoli (2004). Optou-se pela utilização do Mecanalyst, por operar em interface gráfica, facilitando a interação com o programa. Desse modo, os registros da matriz servem como coordenadas para a construção de um mapa hierárquico de valor (MHV), que se baseia na agregação das cadeias dominantes, ou seja, dos caminhos mais incidentes na percepção dos valores e de quais atributos/ consequências conduzem a eles.

\section{Resultados}

Neste tópico são apresentados os resultados obtidos com a pesquisa por meio da técnica laddering com entrevistas, tratamento dos dados, codificação, criação da matriz de implicação e mapa hierárquico de valor. Busca-se evidenciar, assim, as relações existentes entre os atributos do produto identificados pelos consumidores respondentes, e a relação estabelecida com os seus valores de modo a alcançar os objetivos propostos, que consistem na compreensão de elementos concernentes ao comportamento do consumidor de comida japonesa de Fortaleza, Ceará, realçando significados das representações de atributos, consequências e valores percebidos pelos consumidores.

O questionário sociodemográfico permitiu identificar o perfil dos entrevistados, que, em sua maioria (87\%), são do sexo feminino. Na variável faixa etária, houve predominância de indivíduos com idade variando entre 27 e 32 anos (44\%); entre 33 e 38 anos estão 13\% dos entrevistados, e igual percentual é encontrado nos respondentes acima de 45 anos. Em relação ao estado civil, a amostra indica a predominância dos solteiros (67\%) sobre os casados (33\%). No que concerne ao grau de instrução, houve prevalência de consumidores pós-graduados (37\%), seguidos daqueles com nível Superior (33\%) e Superior Incompleto (30\%). Referente à questão "Normalmente você vai ao restaurante", de múltipla escolha, $37 \%$ saem com amigos e $23 \%$ saem acompanhados de namorado ou de namorada.

Para a fase de tratamento dos dados extraídos das 
entrevistas, nos procedimentos da técnica laddering, as expressões e os trechos, citados pelos entrevistados, foram reunidos e categorizados para identificar os códigosresumo correspondentes a atributos, consequências e valores expostos no Quadro 3. Na codificação aplicada a atributos, consideraram-se os aspectos do produto, tais como: aparência (bonito, feio); textura (liso, rugoso); tamanho (pequeno, grande); preço (caro, não muito acessível); características sensoriais, como sabor, cheiro e cor. Quanto à codificação das consequências, de acordo com lista resumo de sinônimos no Quadro 3, foram numerados 16 códigos-resumo. Na codificação dos valores, o parâmetro para tal classificação foi a escala de tipos motivacionais de Schwartz (1992).

Quadro 3 - Lista resumo de sinônimos
Após observação da classificação dos valores no Quadro 4, verificou-se que as dimensões "abertura à mudança” e "autopromoção" se destacaram por concentrar os valores apontados pelos consumidores em estudo. Essa informação permitiu evidenciar um perfil com tendência a dar maior ênfase a valores mais individualistas, reforçando ainda mais a relevância dessas dimensões em tal comportamento. A menção do valor 32 (Satisfação, Prazer, Felicidade), presente no hedonismo, chama a atenção pela importância que o consumidor conseguiu transmitir em relação ao alcance da gratificação pessoal, realçando um comportamento direcionado ao individualismo.

Quanto ao valor 26 (autoestima), que consiste na valorização de si, no cultivo do amor próprio, e ao 31

\begin{tabular}{|ll}
\hline Atributos & Conseqüências \\
\hline 1. Ambiente & 9. Aparência Pessoal \\
2. Características sensoriais & 10. Aproveitar a vida \\
3. Comida crua & 11. Comer bem \\
4. Comida exótica & 12. Confiança \\
5. Exposição do prato & 13. Conhecimento \\
6. Preço & 14. Cuidado com alimentação \\
7. Qualidade & 15. Digestão \\
8. Tamanho & 16. Disposição \\
& 17. Evitar críticas \\
& 18. Massificação, Modismo \\
& 19. Momentos \\
& 20. Não engorda tanto \\
& 21. Reflexão \\
& 22. Romantismo \\
& 23. Sair da rotina \\
24. Vida saùdável & \\
Fonte: Dados da pesquisa.
\end{tabular}

\begin{tabular}{l} 
Valores \\
\hline 25. Abertura \\
26. Autoestima \\
27. Liberdade \\
28. Qualidade de vida \\
29. Realização \\
30. Reconhecimento \\
Social \\
31. Relação afetiva, \\
Amizade \\
32. Satisfação, \\
Prazer, Felicidade \\
33. Uma vida excitan
\end{tabular}

(Relação afetiva, Amizade), presentes no valor Realização, eles também possuem caráter pessoal. Assim, mostram uma busca individual de prazer conduzida por momentos ou ações específicas que envolvem pessoas que complementam o processo de integração, gerando o sentimento de pertencimento, de aceitação, de inclusão. Na dimensão "Abertura à mudança”, o valor Abertura (25), presente no valor Autodireção,

e o valor Uma vida excitante (33), em Estimulação, oferecem boa explicação para uma melhor compreensão acerca do comportamento do consumidor ao pontuar o processo de aculturação, caracterizado pelo aprendizado e pela inserção de outra cultura, hábitos ou valores em seu cotidiano. 
Quadro 4 - Relação entre os valores dos respondentes e os tipos motivacionais de Schwartz.

\begin{tabular}{|c|c|c|}
\hline Dimensão de valor & Tipos motivacionais & $\begin{array}{c}\text { Valores dos consumidores obtidos na } \\
\text { pesquisa }\end{array}$ \\
\hline \multirow{3}{*}{$\begin{array}{l}\text { Abertura } \\
\text { à mudança }\end{array}$} & $\begin{array}{l}\text { Autodireção: independência de pensamento, } \\
\text { ação, opção. }\end{array}$ & 25 - Abertura \\
\hline & Estimulação: excitação, novidade, mudança. & 33 - Uma vida excitante \\
\hline & $\begin{array}{l}\text { Hedonismo: prazer e satisfação sensual para } \\
\text { si mesmo. }\end{array}$ & 32-Satisfação, Prazer, Felicidade \\
\hline \multirow[t]{2}{*}{ Autopromoção } & $\begin{array}{l}\text { Realização: sucesso pessoal, reconhecimento } \\
\text { social. }\end{array}$ & $\begin{array}{l}26 \text { - Autoestima } \\
31 \text { - Relação afetiva, Amizade }\end{array}$ \\
\hline & $\begin{array}{l}\text { Poder: status social, prestígio e controle sobre as } \\
\text { pessoas e os recursos. }\end{array}$ & \\
\hline \multirow{3}{*}{ Conservadorismo } & $\begin{array}{l}\text { Segurança: integridade pessoal e de pessoas e } \\
\text { grupos de identificação. }\end{array}$ & \\
\hline & $\begin{array}{l}\text { Conformidade: cortesia, obediência, honradez. } \\
\text { Moderação de ações que possam prejudicar } \\
\text { terceiros. }\end{array}$ & \\
\hline & $\begin{array}{l}\text { Tradição: respeito e a aceitação dos ideais e } \\
\text { costumes da sociedade a que pertence. }\end{array}$ & \\
\hline \multirow[b]{2}{*}{ Autotranscendência } & $\begin{array}{l}\text { Benevolência: interesse e preocupação com o } \\
\text { bem-estar das pessoas. }\end{array}$ & \\
\hline & $\begin{array}{l}\text { Universalismo: cabeça aberta, justiça social, } \\
\text { igualdade, proteção para o ambiente. }\end{array}$ & \\
\hline
\end{tabular}

Fonte: Tamayo e Schwartz (1993) e dados da pesquisa.

Definidos os códigos identificados na pesquisa, cabe apresentar as conexões entre eles bem como a quantificação dessas conexões por meio da matriz de implicação disposta na Tabela 1.

\subsection{MatRIZ DE IMPLICAÇÃo}

A matriz de Implicação fornece o número de vezes que cada ligação ocorre por meio dos dados das entrevistas. É necessário observar, segundo Vilas Boas (2005), que, ao ser verificada a ocorrência de repetição de uma mesma ligação presente entre dois elementos em única entrevista, considera-se somente uma incidência. Outro fato observado na Matriz de Implicação é a possibilidade de se extrair, em única entrevista, mais de uma ladder (sequência A-C-V). A menção, por parte do respondente, desde os atributos de um produto $(\mathrm{A})$ às consequências de seu uso ou consumo (C) e aos valores pessoais (V), a exemplo de uma cadeia desta pesquisa com os seguintes elementos, do atributo "4. Comida exótica", conduz à consequência psicossocial (23) Sair da rotina, levando à consequência (10) Aproveitar a vida, associando à (19) Momentos, guiando-o à consequência psicossocial "13. Conhecimento", quepode conduzir a três possíveis valores: (31) Relação afetiva, Amizade (terminal); (25) Abertura (instrumental); ou (32) Satisfação, Prazer, Felicidade. As escalas obtidas com base nas entrevistas foram analisadas com referência às relações identificadas e representadas na matriz de implicação. Conforme Vilas Boas (2005, p. 130), “esta fase da pesquisa representa uma quantificação dos dados qualitativos obtidos mediante a análise de conteúdo, característica esta que diferencia a laddering das demais técnicas qualitativas".

De modo a
exemplificar essa
análise, observa-se a
Tabela 1, que mostra
a relação entre o atributo (7) Qualidade e a consequência (11) Digestão, apresentando 12 ligações diretas (à direita) e uma ligação indireta (à esquerda) entre esses elementos $(12,1)$.

Essas ligações identificadas servem de base para a interpretação e para a leitura mais apurada das relações e das percepções dos consumidores. Por meio da matriz de implicação, é possível identificar as relações diretas, sem intermediários, e as relações indiretas, com um ou mais intermediários, mais evidentes, proporcionando o reconhecimento dos atributos, das consequências e dos valores percebidos e as associações estabelecidas. As ligações e a quantificação dessas associações são necessárias à elaboração do mapa hierárquico de valores exposto a seguir. 


\begin{tabular}{|c|c|}
\hline Ambiente & 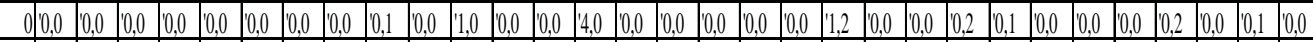 \\
\hline Características sensoriais & 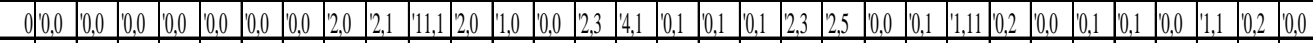 \\
\hline Comida crua & 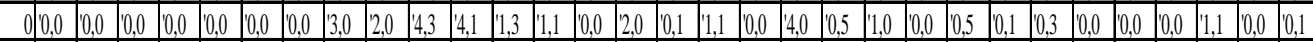 \\
\hline Comida exotica & 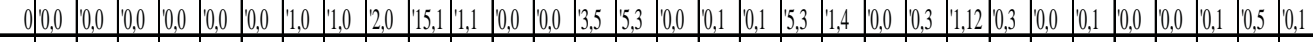 \\
\hline Preco & 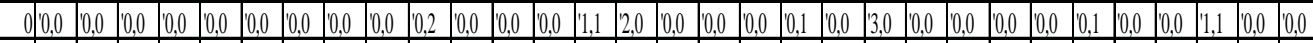 \\
\hline Qualidade & 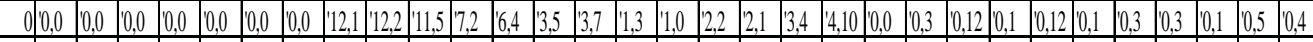 \\
\hline Tamanho & 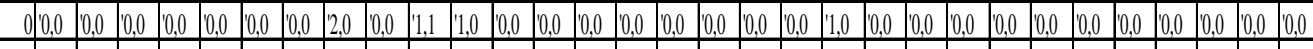 \\
\hline Evitar criticas & 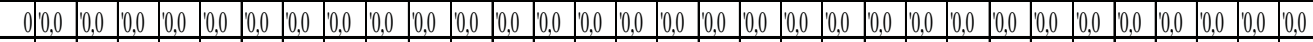 \\
\hline Digestao & 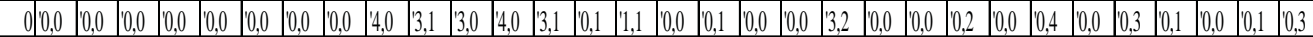 \\
\hline Vida saudável & 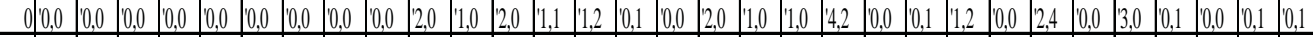 \\
\hline Comer bem & 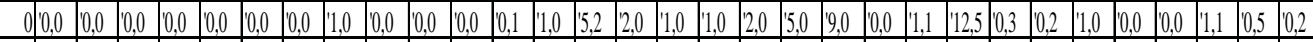 \\
\hline Cuidado alimentacao & 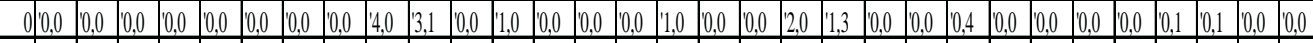 \\
\hline Disposicao & 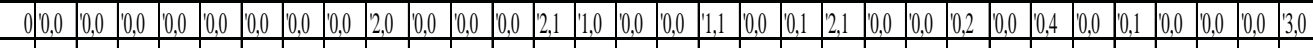 \\
\hline nao engorda tanto & 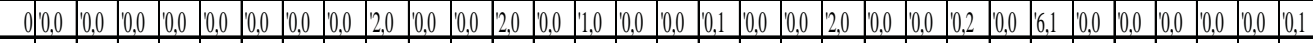 \\
\hline Momentos & 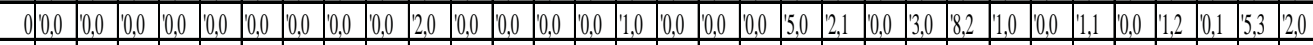 \\
\hline Sairda rotina & 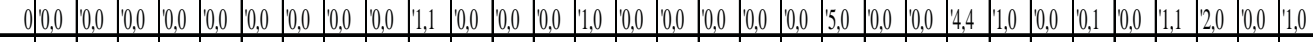 \\
\hline Reflexao & 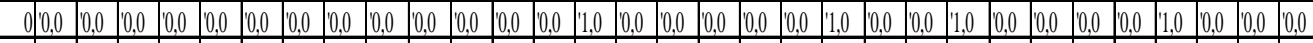 \\
\hline Aparencia Pessoal & 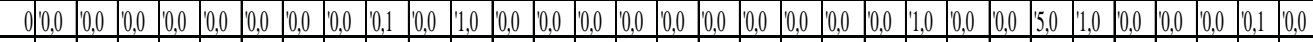 \\
\hline \begin{tabular}{|l|l} 
Confianca \\
\end{tabular} & 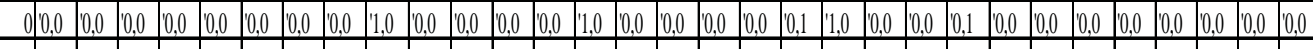 \\
\hline Conhecimento & 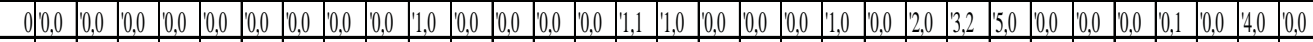 \\
\hline Aproveitar a vida & 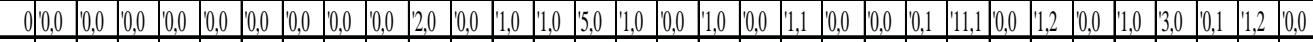 \\
\hline Massificacao, Modismo & \begin{tabular}{|c|c|c|c|c|c|c|c|c|c|c|c|c|c|c|c|c|c|c|c|c|c|c|c|c|c|c|c|} 
& 0 \\
\end{tabular} \\
\hline Romantismo & 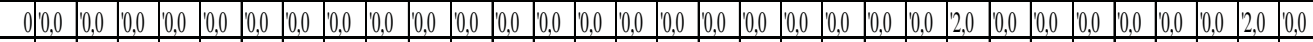 \\
\hline Satisfacao, Prazer, Felicidade & 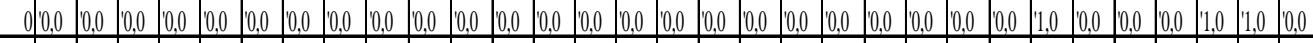 \\
\hline Abertura & 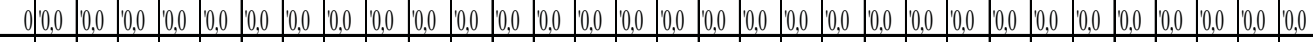 \\
\hline Auto-estima & \begin{tabular}{|l|l|l|l|l|l|} 
\\
\end{tabular} \\
\hline Liberdade & 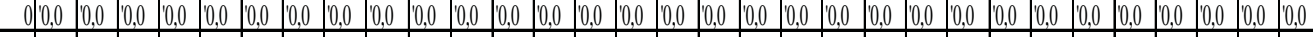 \\
\hline Qualidade de vida & \begin{tabular}{c|c|c|c|c|c|c|c|c|c|c|c|c|c|c|c|c|c|c|c|c|c|c|c|c|c|c|} 
& 0 \\
\end{tabular} \\
\hline Realizacao & 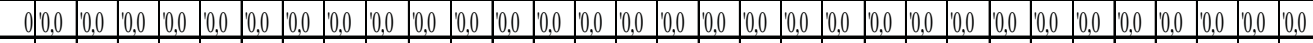 \\
\hline Reconhecimento social & 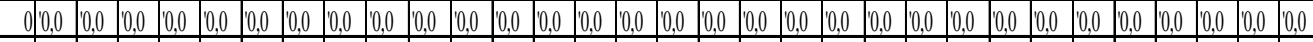 \\
\hline Relacao afetiva, Amizade & 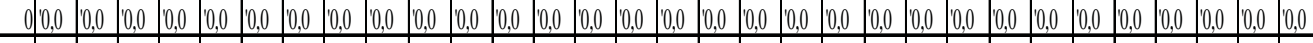 \\
\hline Uma vida excitante & \begin{tabular}{|c|c|c|c|c|c|c|c|c|c|c|c|c|c|c|c|c|c|c|c|c|c|c|c|c|c|c|c|c|c|}
0 & 0 \\
\end{tabular} \\
\hline
\end{tabular}

\subsection{Mapa Hierárquico de Valores e (MHV) E Percepções Dominantes dos Consumidores}

O Mapa Hierárquico de Valores (MHV) apresenta graficamente os atributos, as consequências e os valores de maior frequência. Consiste em uma série de pontos conectados por linhas que representam os agregados dos respondentes da laddering (VRIENS; HOFSTEDE, 2000). O MHV propicia a visualização gráfica de quais atributos do produto conduzem a determinados valores pessoais de seus consumidores, de modo a justificar uma preferência de consumo ou um comportamento de compra (PIMENTA, 2008).

Conforme definido na metodologia deste trabalho, foi utilizado o ponto de corte 4 , que permitiu a redução de 744 ligações totais para 464 ligações ativas, correspondendo a $63 \%$ das ligações totais. O ponto de corte foi reduzido de 33 elementos totais (atributos, consequências e valores) para 21 elementos, com pelo menos 4 ligações cada. Segundo Reynolds e Gutman (1988, p. 20), “um MHV é construído gradualmente conectando todas as cadeias que são formadas considerando as ligações na matriz com significantes relações entre elementos”. É recomendável que o ponto de corte deva conter entre $75 \%$ e $80 \%$ dos relacionamentos presentes na matriz de implicação (REYNOLDS; GUTMAN, 1988). Além dessa recomendação, sugerese que o mapa tenha clareza suficiente para facilitar a visualização das principais cadeias (REYNOLDS; GUTMAN, 1988; MAKATOUNI, 2002; VILAS BOAS, 2005; VILAS BOAS, 2006; PIMENTA et al., 2008). 
Justifica-se, portanto, a escolha pelo ponto de corte 4 para evidenciar as cadeias com atributos, consequências e valores, no mapa, descartando as relações com menos de quatro elementos, porque, apesar de representar 63\% das ligações, essa quantidade permitiu elaborar um MHV claro, destacando as principais cadeias.

A análise do mapa é realizada por meio dessas cadeias formadas, permitindo identificar as percepções dominantes dos consumidores de comida japonesa, bem como obter um conjunto de informações que muito facilitaram a compreensão do comportamento desse consumidor. A Figura 1 apresenta o MHV obtido na pesquisa, e os comentários de sua análise se encontram na sua sequência. A análise desse mapa consistiu na identificação dos elementos-chave, ou seja, os atributos com maior menção entre os respondentes que formaram cadeias significantes as quais conduziram a valores superiores, permitindo maior amplitude na interpretação do consumidor de comida japonesa. Foram identificadas as cadeias advindas dos atributos (1) Ambiente, (2) Características sensoriais, (3) Comida crua, (4) Comida exótica e (7) Qualidade.

A partir do atributo “1. Ambiente”, três cadeias foram formadas, 1-19-13-31, 1-19-13-25 e 1-19-13-32. Esse atributo pode ser interpretado pelo consumidor sob o aspecto do ambiente (infraestrutura) e das condições oferecidas, como limpeza do local, iluminação, espaço, conforto, bem como sensação provocada de bem-estar, tranquilidade, relaxamento, familiaridade e aconchego. A cadeia 1-19-13-31 demonstra que esse tipo de consumidor, ao buscar um serviço que proporcione esse ambiente, pretende, na verdade, atender às necessidades de solidificar suas relações afetivas ao propiciar um momento mais íntimo. Confirma-se, por meio da alta incidência da menção desse valor (31) Relação afetiva, Amizade, o grau de significância para o consumidor no sentido de complementação como ser humano ao estreitar os laços afetivos.

Qualidade é um atributo que merece destaque na análise, nesse mapa, por estabelecer ligação com todas as consequências e todos os valores. Foram formadas dezenove cadeias: 7-33, 7-9, 7-9-26, 7-15-20-26, 7-15-
16-26, 7-15-24-26, 7-15-24-10-19-13-31, 7-15-24-1019-13-25, 7-15-24-10-19-13-32, 7-14-24-26, 7-14-2410-19-13-31, 7-14-24-10-19-13-25, 7-14-24-10-19-1332, 7-14-11-10-19-13-31, 7-14-11-10-19-13-25, 7-1411-10-19-13-32, 7-23-10-19-13-31, 7-23-10-19-13-25, 7-23-10-19-13-32.

O conceito (7) Qualidade reuniu um conjunto bem rico de características que constituem um bom produto na percepção do consumidor de comida japonesa. Falar de qualidade no setor de alimentos é falar de aspectos tangíveis e intangíveis, que estão no próprio produto e ao redor dele. Exemplos disso são: o modo de preparo; o manejo dos ingredientes; o acondicionamento; o tempo de exposição do produto em função de suas peculiaridades, sobretudo em relação à comida japonesa, por conter produtos crus, fazendo-se necessário cuidadoso procedimento para evitar algum tipo de contaminação do alimento. Quando os consumidores, de forma bem significativa, apontam o atributo (7) Qualidade como necessário ao produto, expressam a importância desse conceito no produto e serviço que está agregado.

Com base na análise das cadeias do MHV, foi elaborado o Quadro 5, que visa, de forma sintética, conectar os atributos percebidos pelos consumidores com os respectivos valores pessoais relacionados. Além dessas conexões, observam-se os significados semânticos de tais relacionamentos. 
Figura 1 - Mapa Hierárquico de Valores

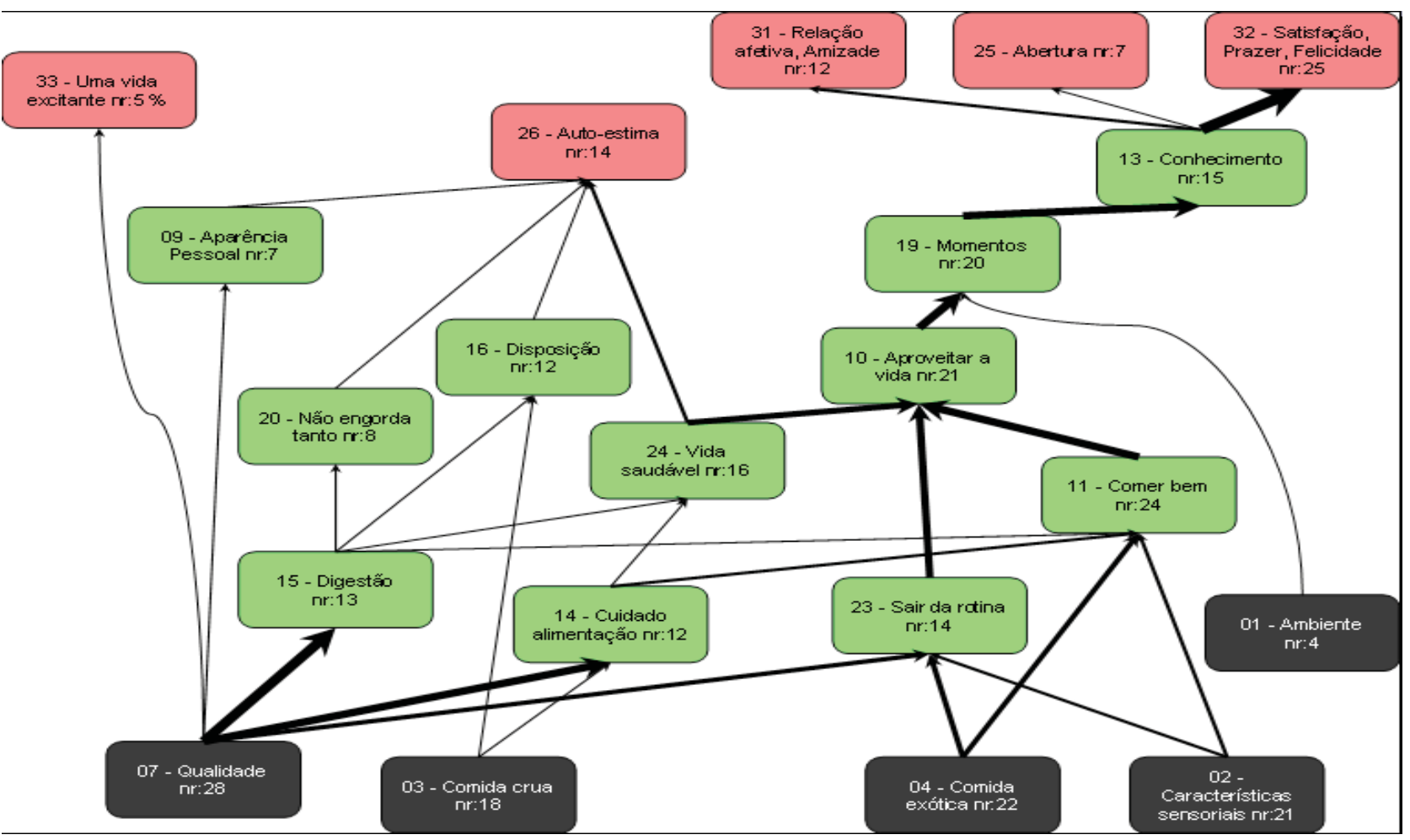

Fonte: Dados da pesquisa.

\begin{tabular}{|c|c|c|}
\hline Atributo & $\begin{array}{l}\text { Valores dos } \\
\text { consumidores de } \\
\text { comida japonesa } \\
\end{array}$ & Percepções do consumidor \\
\hline 1 - Ambiente & \multirow[t]{2}{*}{$\begin{array}{l}\text { Relação afetiva, } \\
\text { Amizade } \\
\text { Abertura } \\
\text { Satisfação, prazer, } \\
\text { felicidade }\end{array}$} & $\begin{array}{l}\text { Crença de que um local tranquilo proporciona um } \\
\text { ambiente de intimidade, melhorando as relações } \\
\text { afetivas e amizade. O ambiente agradável e } \\
\text { aconchegante influencia o processo de abertura a novas } \\
\text { experiências. }\end{array}$ \\
\hline $\begin{array}{l}\text { 2- Características } \\
\text { sensoriais }\end{array}$ & & $\begin{array}{l}\text { A combinação de cheiro, sabor e aparência da comida } \\
\text { tornam a comida atrativa e estimula o apetite do } \\
\text { consumidor, gerando satisfação e prazer ao ingeri-la. } \\
\text { Crença de que a comida colorida é mais saudável, rica } \\
\text { em nutrientes, fazendo bem ao organismo e tornando } \\
\text { possível aproveitar a vida, compartilhar momentos } \\
\text { especiais e felizes. }\end{array}$ \\
\hline 3 - Comida crua & $\begin{array}{l}\text { Autoestima } \\
\text { Relação afetiva, } \\
\text { Amizade } \\
\text { Abertura } \\
\text { Satisfação, prazer, } \\
\text { felicidade }\end{array}$ & $\begin{array}{l}\text { Convicção de que uma comida pode contribuir para } \\
\text { uma vida saudável por não conter frituras, além de não } \\
\text { engordar, o que reflete no cultivo da aparência e na } \\
\text { melhora da autoestima. } \\
\text { Proporciona uma melhor disposição para aproveitar a } \\
\text { vida e poder viver momentos de felicidade. }\end{array}$ \\
\hline 4 - Comida exótica & $\begin{array}{l}\text { Relação afetiva, } \\
\text { Amizade } \\
\text { Abertura } \\
\text { Satisfação, prazer, } \\
\text { felicidade }\end{array}$ & $\begin{array}{l}\text { O conhecimento de outra cultura por meio da comida } \\
\text { denota abertura ao novo. O arranjo do prato, a forma } \\
\text { como é preparada, a sua montagem e a maneira de } \\
\text { comer são diferenças que marcam a comida japonesa, } \\
\text { tornando aquele momento marcante, gerando prazer e } \\
\text { satisfação. } \\
\text { Comer uma comida diferente é sair da rotina, e essa } \\
\text { mudança significa aproveitar a vida e fortalecer os laços } \\
\text { afetivos. }\end{array}$ \\
\hline 7- Qualidade & $\begin{array}{l}\text { Uma vida excitante, } \\
\text { Autoestima, Relação } \\
\text { afetiva, Amizade, } \\
\text { Abertura } \\
\text { Satisfação, prazer, } \\
\text { felicidade }\end{array}$ & $\begin{array}{l}\text { O equilíbrio e a harmonia dos ingredientes deixam o } \\
\text { consumidor mais satisfeito por comer uma comida } \\
\text { bem-feita. O cuidado na alimentação para evitar } \\
\text { doenças e usufruir momentos com amigos e pessoas de } \\
\text { seu ciclo afetivo são outros aspectos positivos. } \\
\text { Qualidade significa comida bem-elaborada, saudável, } \\
\text { leve, afetando diretamente a satisfação do consumidor, } \\
\text { por poder comer um produto bom. }\end{array}$ \\
\hline
\end{tabular}




\section{Conclusões}

A análise realizada do MHV permitiu perceber que o consumidor acredita na influência do ambiente no tocante à possibilidade de proporcionar um clima romântico e íntimo em função da atmosfera envolvente e misteriosa, promovendo a aproximação entre um casal. A tranquilidade do lugar incita o diálogo entre pessoas que compartilham momentos e interesses em comum, fortalecendo o verdadeiro sentimento de amizade. O consumidor quer descontração, quer bem-estar, isto é, quer ser feliz. Observa-se que existe o desejo, a curiosidade para fazer descobertas. Portanto, a expansão, a abertura para conhecer novos hábitos alimentares, ou mesmo adquiri-los, é uma forma de se renovar, ser mais flexível e, por fim, aprender para de fato crescer. Características sensoriais, como sabor, cor e cheiro, podem, além de despertar o apetite, evocar a ideia de alegria, limpeza e energia. Portanto, um prato colorido significa comer bem, o que provoca no consumidor a impressão de bem-estar físico e mental, por ele julgar ser uma boa opção para a saúde. Poder comer bem constitui usufruir uma das ações prazerosas que a vida oferece, proporcionando um estado elevado de satisfação. Apreciar aquele sabor, na verdade, para o consumidor, é o momento reservado para ficar perto, estreitar os laços, trocar confidências, construir uma história com o outro, que pode ser o amigo, o irmão, o esposo, o pai ou a mãe. Esse sabor e esse cheiro da comida japonesa estão associados à união, à harmonia e à alegria, o que pode ser traduzido em felicidade. A comida japonesa é caracterizada como exótica pelo consumidor, o que revela que ele procura uma comida diferente do convencional a fim de preencher sua vida de satisfação e prazer. A busca pelo conhecimento de novos sabores está relacionada a um momento especial compartilhado. A amostra de consumidores entrevistada gosta de se sentir diferente, sofisticada e eclética. O que, onde e como consumir são maneiras encontradas pelo consumidor para comunicar um pouco de si aos outros. O entrevistado nesta pesquisa acredita que a conservação das propriedades naturais na comida crua auxilia na obtenção de saúde, de disposição e de uma vida com mais qualidade. Destaca-se que todos têm a ânsia de aproveitar a vida junto com as pessoas estimadas. Portanto, a saúde é fator crítico para o entrevistado, visto que a ausência dela implica uma série de impedimentos, inclusive ter acesso a determinados alimentos e lugares. Verifica-se, portanto, de acordo com as percepções dos respondentes, uma associação de comida crua com comida natural, que agride menos o organismo, proporcionando benefício à pele e à aparência pessoal e retardando as marcas do tempo. Significa dizer que o consumidor tem uma preocupação com sua aparência em função das pressões sociais que repercutem também na sua autoestima. De acordo com os resultados da pesquisa, é possível verificar que esse consumidor tende a valorizar o ambiente para apreciar a comida japonesa, visto que esse consumo possui um traço hedônico, caracterizado pela busca da satisfação pessoal. Complementa-se o entendimento do comportamento do consumidor de comida japonesa dizendo que ele está aberto a mudanças, motivado a conhecer o novo, ou seja, está em contato com novas ofertas do mercado, permitindo-se viver novas experiências e transformar isso em conhecimento, momentos e lembranças que farão parte de sua vida. Não foi identificado nenhum valor, apontado pelos entrevistados, considerado como coletivo, o que fortalece a caracterização do perfil do consumidor de comida japonesa de Fortaleza, preocupado com o bem-estar e com a satisfação pessoal, com tendência a valorizar aspectos, pessoas, produtos e serviços que afetam direta ou indiretamente os seus objetivos superiores. Lazer, momentos para relaxar, encontrar pessoas, essas são algumas variáveis com que donos de restaurantes e empresas do ramo devem se preocupar, além do ambiente, que complementará o processo de busca de gratificação pessoal por parte do consumidor. Face ao atendimento às recomendações da literatura e ao arcabouço teórico da pesquisa, não é possível aqui fazer qualquer tipo de generalização. Portanto, os resultados obtidos são perspectivas que poderão delinear o comportamento desses consumidores de comida japonesa de Fortaleza, oferecendo uma base de segmentação mais restrita. Há ausência? de dados estatísticos oficiais que apontem as tendências de consumo, por exemplo, o consumo médio anual de comida japonesa por Estado, de modo a contribuir na construção de um perfil desse consumidor. O Laddermap software, apesar de apresentar a vantagem de ser gratuito, possui algumas fragilidades e inconsistências quanto ao armazenamento dos dados inseridos, não oferecendo muitos recursos ao usuário. 
A relevância dessas informações consiste em direcionar as decisões sobre as estratégias de marketing concernentes ao desenvolvimento de produto, serviço e utilização de comunicação mais eficaz, de modo a relacionar os atributos dos produtos, as consequências ou os benefícios de consumo com os valores dos consumidores. É interessante que as organizações do setor de alimentos do mercado de Fortaleza conheçam os seus consumidores, a fim de identificar o que de fato eles valorizam e como é a relação deles com o produto ofertado. Considerando os resultados obtidos nesta pesquisa, acredita-se que empresas atuantes no setor de alimentos, especialmente de comida japonesa, possam desenvolver ações de marketing fundamentadas nas percepções dos consumidores orientadas por valores. As estratégias podem explorar os atributos destacados pelos consumidores, como melhorias no ambiente, no produto, e no serviço. A qualidade, o requinte, a delicadeza, a preservação do sabor, bem como o ritual que cerca a comida japonesa podem servir de meios na formulação e na utilização de estratégias na conquista e na retenção dos consumidores que buscam atingir estados-fim desejados, identificados neste trabalho. Por fim, registra-se que este trabalho foi um novo caminho aberto a ser trilhado no vasto campo da pesquisa empírica de marketing, sugerindo, portanto, o desenvolvimento de novas investigações que envolvam outras perspectivas que complementem os limites deste estudo e cooperem na construção do conhecimento sobre o comportamento do consumidor.

\section{REFERÊNCIAS}

ENGEL, J. F.; BLACWELL, R. D.; MINIARD, P. W. Comportamento do Consumidor. 8. ed. Rio de Janeiro: Livros Técnicos e Científicos, 2000.

FERRAN, Florence de; GRUNERT, Klaus G. French fair trade coffee buyers' purchasing motives: An exploratory study using means-end chains analysis. Food Quality and Preference, v. 18, n, 2, p.218-229, March. 2007. <http:// dx.doi.org/10.1016/j.foodqual.2005.11.001>

GENGLER, C. Laddermap User's Manual. Camden, New Jersey, 1995.

GOUVEIA, V. V.; MARTINEZ, E.; MEIRA M.; MILFONT, T. L. A estrutura e o conteúdo universais dos valores humanos: análise fatorial confirmatória da tipologia de Schwartz. Estudos de Psicologia, v. 6, n. 2, p. 133-142, 2001.

GUTMAN, J. A Means-End Chain Model based on consumer categorization processes. Journal of Marketing, Chicago, v. 46, n. 2, p. 60-72, Spring 1982. <http://dx.doi. org/10.2307/3203341>

GUTMAN, J. Exploring the nature of linkages between consequences and values. Journal of Business Research, New York, v. 22 n. 2, p. 143-148. 1991. <http://dx.doi. org/10.1016/0148-2963(91)90048-3>

KAMAKURA, A. W.; NOVAK, P. T. Value-System Segmentation: exploring the meaning of LOV. Journal of Consumer Research, v. 19, June. 1992. <http://elabresearch.ucr.edu/blog/uploads/publications/Kamakura_ Novak_1992_JCR.pdf>

KOLAR, T. Linking customers and products by meansend chain analysis. Management, v. 12, 2, p. 69-83, 2007.

KRYSTALLIS, A., MAGLARAS, G, MAMALIS, S. Motivations and cognitive structures of consumers in their purchasing of functional foods. Food Quality and Preference, v. 19, p. 525-538. 2008. <http://dx.doi. org/10.1016/j.foodqual.2007.12.005>

LEÃO, A. L. M. S.; MELLO, S. C. B. Estratégias de comunicação através do conhecimento dos valores dos usuários: aplicação do modelo Meccas para um jornal online. In: CONGRESSO BRASILEIRO DE CIÊNCIAS DA COMUNICAÇÃO, 2001. Campo Grande. Anais... Campo Grande: Intercom, 2001.

MAKATOUNI, A. What motivates consumers to buy organic food in the UK?: Results from a qualitative study. British Food Journal, Bradford, v. 104, n. 3/5, p. 345-352. 2002. <http://dx.doi.org/10.1108/00070700210425769> MALHOTRA, N. K. Pesquisa de Marketing: uma orientação aplicada. Porto Alegre: Bookman, 2001, 720 p.

NASPETTI, S.; ZANOLI, R. Do Consumers Care About Where They Buy Organic Products? A Means-End Study with Evidence from Italian Data. In: BAOURAKIS, G. (ed.). Marketing Trends for Organic Food in the 21st Century. 1. ed. Cingapura: World Scientific, v. 3, p. 238255, 2004.

PADEL, S., FOSTER, C. Exploring the gap between attitudes and behaviour: understanding why consumers buy or do not buy organic food. British Food Journal, Bradford, v. 107, n. 8, p. 606-625. 2005. <http://dx.doi. org/10.1108/00070700510611002> 
PIMENTA, M. L.; VILAS BOAS, L. H. B.; MELO, D. C.; NUNES, E. F.; BOAVENTURA, E. A Percepção de Valores na Seleção de Lojas do Varejo Alimentar: Uma Investigação Empírica nas Cidades de Uberlândia e Uberaba. In: ENCONTRO DA ANPAD, 31, 2007, Rio de Janeiro. Anais do XXXI do ANPAD. Rio de Janeiro: Anpad, 2007.

PIMENTA, M. L. Comportamento do Consumidor de Alimentos Orgânicos na Cidade de Uberlândia: um estudo com base na cadeia de meios e fins. 2008. 124 p. Dissertação (Mestrado em Administração). Universidade Federal de Uberlândia. Uberlândia, 2008.

PIMENTA, M. L.; MELO, D. C.; VILAS BOAS, L. H. B.; SILVA, A. Lago da; SETTE, R. S. Bases de segmentação por valores: um estudo sobre o mercado consumidor de orgânicos da cidade de Uberlândia. Teoria e Evidencia Econômica (UPF), v. 14, p. 142-165, 2008.

PIMENTA M. L., YOKOYAMA, M. H., VILAS BOAS, L. H. B., MORIGUCHI, S. N., MACEDO J. F. P. C. “Ser Regional” e a percepção de valor do consumidor - um estudo de marcas regionais de laticínios em Lavras-MG. XXXIII Encontro da Anpad. São Paulo-SP, 19-23 de setembro de 2009.

PORTO, J. B.; TAMAYO, A. Escala de Valores Relativos ao Trabalho - EVT. Psicologia: Teoria e Pesquisa, v. 19, n. 2, p. 145-152, maio/ago. 2003.

REYNOLDS, T. J.; GUTMAN, J. Laddering theory, method, analysis and interpretation. Journal of Advertising Research, New York, v. 28, n. 1, p. 11-31, Feb./Mar., 1988. <http://www.uta.edu/faculty/richarme/MARK\%20 5338/Reynolds\%20and\%20Gutman\%20laddering\%20 article.pdf>

REYNOLDS, T. J.; GENGLER, C. E.; HOWARD, D. J. A means-end analysis of brand persuasion through advertising. International Journal of Research in Marketing, Amsterdam, v. 12, n. 3, p. 257-266, Sept. 1995. <http:// dx.doi.org/10.1016/0167-8116(95)00025-W>

ROKEACH, Milton, The role of values in public opinion research. California. v. 9, May, 1968.

ROKEACH, M. The nature of human values. New York: Free Press, 1973.

SALVI, Rodrigo D. de. Um mesmo cliente, muitas possibilidades. Revista Gestão Organizacional, v. 1, n. 2, Jul./ Dez. 2008.

SAMPAIO, J. A. do C.. Comportamento do Consumidor de comida japonesa: um estudo sobre atributos e valores.
2009. 101 p. Dissertação (Mestrado em Administração). Universidade Federal do Ceará, 2009.

SCHWARTZ, S. H.; SAGIE, G. Value consensus and importance a cross-national study. Journal of Cross-Cultural Psychology, v. 31, n. 4, p. 465-497, July. 2000. <http:// dx.doi.org/10.1177/0022022100031004003>

SCHWARTZ, S. H. Universals in the content and structure of values: theory and empirical tests in 20 countries. Advances in Experimental Social Psychology, San Diego, v. 25, p. 1-65, 1992. <http://dx.doi.org/10.1016/S00652601(08)60281-6>

SCHWARTZ, S. H.; BILSKY, W. Toward a theory of the universal content and structure of values. Journal of Personality and Social Psychology, Washington, v. 53, n. 3, p. 550-562, Sept. 1987

SOLOMON, M. R. O Comportamento do Consumidor: comprando, possuindo e sendo. 5ed. Porto Alegre: Bookman, 2002.

TAMAYO, A.; SCHWARTZ, S. H. Estrutura motivacional dos valores humanos. Psicologia: Teoria e Pesquisa, v. 9, p. 329-348, 1993.

TAUBER, E. M. Why do People Shop? Journal of Marketing, v. 36, p. 46-49, Oct. 1972.

VELUDO DE OLIVEIRA, T. M.; IKEDA, A. A. Usos e limitações do método laddering. Revista de Administração, São Paulo, v. 5, n. 1, p. 197-222. 2004.

VELUDO DE OLIVEIRA, T. M., IKEDA A. A.; CAMPOMAR M. C. Laddering in the practice of marketing research: barriers and solutions. Qualitative Market Research. v. 9 n. 3, p. 297-306. 2006. <http://dx.doi. org/10.1108/13522750610671707>

VILAS BOAS, L. H. de B. Comportamento do consumidor de produtos orgânicos: uma análise na perspectiva da teoria da cadeia de meios e fins. 2005. 222 p. Tese (Doutorado em Administração) - Universidade Federal de Lavras, Lavras, 2005.

VILAS BOAS, L. H. B.; SETTE, R. de S.; BRITO, M. J de. Perspectivas da antropologia no estudo do comportamento do consumidor: Contribuições para o desenvolvimento da teoria e pesquisa em marketing. REAd - Edição 50, v. 12, n. 2, mar./abr. 2006.

VILAS BOAS, L. H. de B.; SETTE, R. de S.; PIMENTA, M. L. Comportamento do consumidor e alimentos orgânicos na cidade de Uberlândia: uma aplicação da técnica laddering. SOBER. XLVI Congresso da Sociedade Brasileira de Economia, Administração e Sociologia Ru- 
ral. Rio Branco - Acre, 20 a 23 de julho de 2008.

VRIENS, M.; HOFSTEDE, F. T. Linking attributes, benefits, and consumer values. Journal of Marketing Research; Chicago, Fall. 2000. 